\title{
The intraoperative pathological findings in cases of chronic suppurative otitis media with central perforation of tympanic membrane at a tertiary care centre in Eastern Nepal
}

\author{
Sanjeev Kumar Thakur ${ }^{1,2}$, Nisha Ghimire ${ }^{3}$, Rabin Acharya², Sanjay Kumar Singh ${ }^{4}$, \\ Anwar Afaque ${ }^{5}$ \\ ${ }^{1}$ Lecturer, Department of ENT \& HNS, Nobel Medical College, ${ }^{2}$ Consultant, Biratnagar Eye Hospital, \\ ${ }^{3}$ Assistant Professor, Department of Physiology, Nobel Medical College, ${ }^{4}$ Professor, Department of Ophthalmology, \\ National Academy of Medical Sciences, Kathmandu, Programme Director, Eastern Regional Eye Care Programme, \\ ${ }^{5}$ Health Educator, Biratnagar Eye Hospital, Biratnagar, Nepal
}

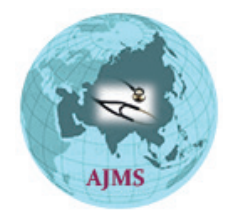

A B S T R A C T

Background: Chronic suppurative otitis media (CSOM) is the chronic inflammation of the middle ear cleft. The atticoantral type is called unsafe type because of the associated complications due to granulations and cholesteatoma which may be life-threatening. CSOM with central perforation (tubotympanic type) is usually not associated with major complications such as cholesteatoma formation. Aims and Objectives: To find out the intraoperative pathological findings in cases of CSOM with central perforation (tubotympanic type). Materials and Methods: This descriptive, cross sectional study has been conducted in the Department of Ear, Biratnagar Eye Hospital in Nepal over 2 years. Study group includes 172 patients having CSOM with central perforations in the tympanic membranes who underwent different types of procedures. Preoperatively, all the patients were evaluated with otoscopy, microscopy, pure-tone audiometry, and some patients with computed tomography scan. The pathological findings were confirmed with biopsy. The findings were tabulated and analysed. Results: Twenty-one (12.2\%) patients were having dry central perforation with normal Eustachian tube function. Ninty-five patients, i.e., $55.23 \%$ were having granulations in attic, aditus, antrum. $25(14.53 \%)$ cases were having ossicular erosion.5 (2.9\%) cases had tympanosclerosis in middle ear. $1(0.58 \%)$ case had facial nerve dehiscence. $16(9.3 \%)$ cases had oedema of middle ear mucosa/aural polyp from middle ear. Surprisingly 9 patients, i.e., $5.23 \%$ were having cholesteatoma which was confirmed by histopathological study. Conclusion: This study shows that cholesteatoma can be found in tubotympanic type of CSOM, along with other pathological findings. Hence it is on the part of the surgeon to be careful while planning surgery on their patients with CSOM (tubotympanic type), remembering that all safe CSOM might not always be safe.

Key words: Central perforation, Cholesteatoma, Chronic Suppurative Otitis Media, Mastoidectomy, Safe ear

\section{INTRODUCTION}

Chronic suppurative otitis media (CSOM) is the chronic inflammation of the middle ear cleft which is composed of Eustachian tube, hypotympanum, mesotympanum,
Access this article online

Website:

http://nepjol.info/index.php/AJMS DOI: 10.3126/ajms.v8i1.15944 E-ISSN: 2091-0576

P-ISSN: $2467-9100$ 
ear cleft and changes in the mucosa of the middle ear secondary to eustachian tube dysfunction may all contribute to the development of chronic otitis media. ${ }^{2}$

Clinically CSOM is of two types- tubotympanic type (safe) and atticoantral type (unsafe) depending on the likelihood of developing complications, occasionally that can be life threatening. ${ }^{3}$

These complications are mainly due to the granulation tissue and cholesteatoma causing bone erosion and necrosis which may involve the vital structures such as facial nerve, inner ear, and intracranial components. These also erode the ossicles causing hearing loss. The tubotympanic types are mainly complicated with hearing loss which may be due to perforation in the tympanic membrane or ossicular chain erosion/fixation. Mechanism of ossicular erosion in non-cholestatomatous middle ear disease is overproduction of cytokines-TNF alpha, interleukin-2, firoblast growth factor, and platelet derived growth factor which promotes hypervascularization, osteoclast activation, and bone resorption causing ossicular damage. ${ }^{4}$ In tubotympanic disease, marginal perforations are more sinister, because it sometimes is associated with cholesteatoma formation. ${ }^{5}$

Central perforations are considered safe as cholesteatoma is usually not associated with them. Central perforations may be anterior, posterior, inferior (in respect to handle of malleus), and subtotal. Again central perforation may be dry or active, giving history of intermittent profuse mucoid discharge. Rarely, the discharge is continuous and malodorous. Discharge is precipitated by passage of water through perforation and upper respiratory tract infection. ${ }^{6}$

The diseases usually found in active central perforations are granulation tissue and polyp formation. Ossicular chain fixation or erosion may be found in both active and dry central perforations.

Inspite of tubotympanic type of CSOM considered safe and not associated with cholesteatoma, there have been reports of cholesteatoma being found in case of central perforations, although the prevalence is very low.

In a study done by Rout and colleagues, the prevalence of cholesteatoma in chronic suppurative otitis media with central perforation was found in $3.4 \%$ of the study sample. ${ }^{7}$ In a study done by Sandeep and colleagues, intraoperative finding showed around $66 \%$ cases with granulation in attic, aditus and antrum. Surprisingly 2\% cases had cholesteatoma sac and histopathological finding of the specimens taken showed cholesteatoma in $8 \%$ of cases. ${ }^{8}$ Similarly, in a Japanese study, 28 of 2948 ears with central perforation of the Tympanic membrane had cholesteatoma.'
Hence considering the above facts, this study was undertaken to find out the intraoperative findings in cases of CSOM with central perforation (tubotympanic type) who underwent surgery at Biratnagar Eye Hospital in the Department of Otology.

\section{MATERIALS AND METHODS}

This descriptive, cross sectional study has been conducted over a period of 2 years in the Department of Otology, Biratnagar Eye Hospital, Biratnagar, Nepal. Total patients studied during the period were 172 .

\section{Inclusion criteria}

1. Patient of CSOM with central perforation which may be active or dry.

2. Patient willing for surgery and giving consent for the study.

3. Patient willing to come for regular follow up and follow the medical advice.

\section{Exclusion criteria}

1. Patient not willing and not giving consent for the study.

2. Patient of CSOM with other types of perforations except central type.

3. History of previous surgery.

The patients considered for the study were evaluated properly with detailed history taking, thorough clinical examination by otoscopy, examination under microscope, hearing assessment by pure-tone audiometry, $x$-rays of mastoid region, tests for Eustachian tubes function, and culture and sensitivity test whenever required. Eustachian tube function test was done by valsalva test, or simply by putting ear drops in the ear and asking for bitter tests in the throat. Computed tomography (CT) scan was done in some cases to exclude middle ear and mastoid pathology to assess the ossicular chain status and status of the facial canal and semicircular canals. Routine blood investigations were done.

Patients with dry central perforations of tympanic membrane for more than 6 months, with normal Eustachian tube function, were offered only tympanoplasty despite the status of mastoid air cell system on X-ray.

Rest of the patients underwent cortical mastoidectomy with tympanoplasty except in patients with extensive diseases of middle ear and mastoid, i.e., cholesteatoma and granulation. Since the complete eradication of the disease was not possible, we preferred modified radical mastoidectomy with or without tympanoplasty in those cases. 
All the patients were evaluated under microscope during surgery and biopsy was done to confirm the pathological findings. The results were tabulated and expressed in number and percentage.

\section{RESULTS}

Out of 172 patients we studied, 104 (60.47) were males and 68 (39.53) were females, as shown in Table 1. The mean age was 28.68 years. The minimum age was 14 and maximum age was 75 years.

Most of our patients were of younger age group with maximum in the range of $21-30$ years i.e. $33.7 \%$, as shown in Table 2.

One-hundred eleven (64.53\%) cases had unilateral disease of ear with right ear affected in $72(41.86 \%)$ cases \& left ear affected in $39(22.67 \%)$ cases, while $61(35.47 \%)$ cases had bilateral diseased ear. The mean duration of disease in the ear was 8.61 years. $23.8 \%$ were smokers. $66.3 \%$ of the patients had history of bathing in pond with no precautions to restriction of water entry in ears, as shown in Table 3.

All those patients came with various symptoms and the chief complaint was as shown in the Table 4.

Eighteen (10.46\%) cases had no complaint. However, 74 $(43.02 \%)$ patients had history of recurrent mucopurulent discharge of ears. The second commonest chief complaint was earache in $32(18.6 \%)$ cases. Other symptoms like decreased hearing (28 I.e. $16.27 \%$ cases), tinnitus (12 i.e. $6.97 \%$ cases) and transient vertigo ( 2 i.e. $1.16 \%$ cases) were also found. Interestingly, $6(3.48 \%)$ patients complained of intermittent foul smelling discharge.

On otoscopic examination of the ears posted for surgery, $86(50 \%)$ cases had large central perforation, $75(43.6 \%)$ cases had subtotal and $11(6.39 \%)$ cases had small perforation, as shown in Table 5 .

On estimating the hearing loss, no hearing loss was found in $9(5.23 \%)$ cases. Conductive hearing loss was found in $149(86.63 \%)$ cases, while, mixed hearing loss was found in 14(8.14\%) cases, as shown in Table 6.

After preoperative evaluation, these cases underwent following procedures as shown in Table 7. Maximum number of cases had cortical mastoidectomy with tympanoplasty i.e. $104(60.46 \%)$ cases. Only tympanoplasty was offered in $21(12.2 \%)$ cases. However, $47(27.32 \%)$ cases underwent modified radical mastoidectomy with tympanoplasty (outside in approach) due to extensive

\begin{tabular}{lc} 
Table 1: Mean and range of age distribution & \\
\hline Total number of cases & 172 \\
Mean age & 28.68 \\
Minimum age & 14 \\
Maximum age & 75 \\
\hline
\end{tabular}

\begin{tabular}{lccc}
\multicolumn{4}{l}{ Table 2: Age distribution } \\
\\
\hline Age group in years & Male & Female & Percentage \\
\hline$<=20$ & 35 & 15 & 29 \\
$21-30$ & 28 & 30 & 33.7 \\
$31-40$ & 28 & 14 & 24.4 \\
$41-50$ & 9 & 9 & 10.5 \\
$51-60$ & 1 & 0 & 0.6 \\
$61-70$ & 2 & 0 & 1.2 \\
$>70$ & 1 & 0 & 0.6 \\
\hline
\end{tabular}

\begin{tabular}{lc} 
Table 3: Associated factors & \\
\hline The mean duration of disease in the ear & 8.61 years \\
Diseased contralateral Ear & $61(35.46 \%)$ \\
Smokers & $41(23.8 \%)$ \\
Bathing in ponds/no precautions to entry of water & $114(66.3 \%)$ \\
in diseased ears & \\
\hline
\end{tabular}

\begin{tabular}{lcc} 
Table 4: Chief complaint $(\mathbf{n = 1 7 2})$ & \\
\hline Chief complaint & $\begin{array}{c}\text { Number of } \\
\text { patients }\end{array}$ & Percentage \\
\hline No complaints & 18 & 10.46 \\
Decreased hearing & 28 & 16.27 \\
Discharging ears (continuous, & 74 & 43.02 \\
intermittent) & 12 & 6.97 \\
Tinnitus & 32 & 18.6 \\
Ear pain & 6 & 3.48 \\
Intermittent foul smelling & & 1.16 \\
discharge & 2 & \\
Transient vertigo & & \\
\hline
\end{tabular}

\begin{tabular}{lcc} 
Table 5: Type of perforation & \\
\hline Type of perforation & Number & Percentage \\
\hline Small & 11 & 6.39 \\
Large & 86 & 50 \\
Subtotal & 75 & 43.6 \\
\hline
\end{tabular}

\begin{tabular}{lccc} 
Table 6: Type of hearing loss & & \\
\hline $\begin{array}{l}\text { Type of } \\
\text { hearing loss }\end{array}$ & $\begin{array}{c}\text { No hearing } \\
\text { loss }\end{array}$ & Conductive & Mixed \\
\hline Number & 9 & 149 & 14 \\
Percentage & 5.23 & 86.63 & 8.14 \\
\hline
\end{tabular}

\begin{tabular}{lcc}
\multicolumn{3}{l}{ Table 7: Type of surgery done } \\
\hline Type of surgery done & Number & Percentage \\
\hline Only tympanoplasty & 21 & 12.2 \\
$\begin{array}{l}\text { Cortical mastoidectomy with } \\
\text { tympanoplasty }\end{array}$ & 104 & 60.46 \\
$\begin{array}{l}\text { Modified radical mastoidectomy } \\
\text { with tympanoplasty }\end{array}$ & 47 & 27.32 \\
\hline
\end{tabular}


disease of middle ear and mastoid. The aditus was patent in only $27(17.88 \%)$ cases, while it was blocked in 124 $(82.12 \%)$ cases, as shown in Table 8.

After proper evaluation using different methods of investigations combined with biopsy of the suspected lesions following predominant pathological findings were found, as shown in Table 9. Twenty-one(12.2\%) patients were having dry central perforation with normal Eustachian tube function. Ninety-five patients, i.e., 55.23\% were having granulations in attic, aditus, antrum. Twenty-five (14.53\%) cases were having ossicular erosion. ${ }^{5}(2.9 \%)$ cases had tympanosclerosis in middle ear. $1(0.58 \%)$ case had facial nerve dehiscence. $16(9.3 \%)$ cases had oedema of middle ear mucosa/aural polyp from middle ear. Surprisingly 9 patients, i.e., $5.23 \%$ were having cholesteatoma which was confirmed by histopathological study.

\section{DISCUSSION}

Chronic suppurative otitis media is a disease of young adults and about $33.7 \%$ of the patients were between the ages of 21-30 years, which is comparable to the study done by group of workers in cases of tubotympanic type of CSOM. ${ }^{8,10}$ The ratio of male to female patients was $1.53: 1$, showing male predominance; similar findings have been reported by several other authors. ${ }^{8,11-13}$ Onehundred -eleven (64.53\%) cases had unilateral disease of ear with right ear affected in $72(41.86 \%)$ cases and left ear affected in $39(22.67 \%)$ cases, while $61(35.47 \%)$ cases had bilateral diseased ear. The mean duration of disease in the ear was 8.61 years. There was more laterality to right ear $(41.86 \%)$ in our study, similar to a study done in India. ${ }^{8}$

Twenty-three point eight percent were smokers in our study. Sixty-six percent of the patients had history of bathing in

\begin{tabular}{lcc} 
Table 8: Status of patency of aditus & \\
\hline Status of patency of aditus & Number & Percentage \\
\hline Patent & 27 & 17.88 \\
Blocked & 124 & 82.12 \\
\hline
\end{tabular}

\begin{tabular}{lcc}
\multicolumn{3}{l}{ Table 9: Intraoperative findings } \\
\hline Type of pathology (predominantly) & Number & Percentage \\
\hline Dry central perforation with normal & 21 & 12.2 \\
Eustachian tube function and no & & \\
other pathology & & \\
Granulation in attic, aditus, antrum & 95 & 55.23 \\
Ossicluar erosion & 25 & 14.53 \\
Tympanosclerosis in middle ear & 5 & 2.9 \\
Facial nerve dehiscence & 1 & 0.58 \\
Oedema of Middle ear mucosa/Aural & 16 & 9.3 \\
polyp of middle ear & & \\
Choleasteatoma & 9 & 5.23 \\
\hline
\end{tabular}

pond with no precautions to restriction of water entry in ears. Albu et al in 2012, in a study of 320 cases, found that three factors were significant in predicting success rate, that is, healthy opposite ear, a long dry period preceding the operation, and non-smoker status. The only factor attaining significance in the multivariate analysis was a dry period longer than 3 months. ${ }^{14}$

On otoscopic examination of the ears posted for surgery, 86 $(50 \%)$ cases had large central perforation, $75(43.6 \%)$ cases had subtotal and $11(6.39 \%)$ cases had small perforation. In the study by Sandeep and colleagues large central and subtotal perforation were common, similar to our study. ${ }^{8}$

Among the pattern of hearing loss, this series showed that $86.63 \%$ patients had conductive type of hearing loss, $8.14 \%$ had mixed type. Conductive type of hearing loss was the most common type and this was consistent with other study. 8,15

The goal of tympanic membrane repair in tubotympanic type of CSOM is to close the perforation, remove the disease and improve hearing of the patient. Tympanoplasty is an established procedure for tympanic membrane perforation repair. But, now the quest is on to improve the results further by studying the different influencing factors. Recently many studies have been undertaken to evaluate the role of cortical mastoidectomy to improve the results of tympanoplasty. ${ }^{16,17}$ Mastoid factors include the extent of mastoid pneumatization and the presence of inflammatory disease in the mastoid. Holmquist and Bergstrom first suggested that mastoidectomy improves the chance of successful tympanoplasty for patients with noncholesteatomatous chronic otitis media. They maintained that creation of an aerated mastoid enhances success in patients with poor tubal function or a small mastoid air cell system. ${ }^{18}$

Thus, simple closure of a perforation in active mucosal chronic otitis media without surgical removal of infected mucosa and granulation tissue from the mastoid is fraught with failure to control the disease. ${ }^{19}$ Mastoidectomy impacted the clinical course in patients by reducing the number of patients requiring future procedures and by decreasing disease progression. ${ }^{20}$ Sheehy in 1985 recommended performing simple cortical mastoidectomy routinely for all tympanoplasties because it is "good practice" and because "it's better to be safe than sorry." 21

Out of the predominant pathological findings preoperatively, $21(12.2 \%)$ patients were having dry central perforation with normal Eustachian tube function and all of them underwent only tympanoplasty. In the study by Rout and colleagues, $48.6 \%$ had above finding. ${ }^{7}$ 
Rest of the cases underwent mastoidectomy. One hundred twenty-four $(82.12 \%)$ cases had blocked aditus that was cleared. Ninety-five patients, i.e., $55.23 \%$ were having granulations in attic, aditus, antrum. In the study by Sandeep and colleagues, $66 \%$ had granulation. ${ }^{8}$ However, only, 20 cases $(9.5 \%)$ in the study by Rout and colleagues had granulation. ${ }^{8}$

Twenty-five (14.53\%) cases were having ossicular erosion, $5(2.9 \%)$ cases had tympanosclerosis in middle ear and $1(0.58 \%)$ case had facial nerve dehiscence in our study. Eleven $(11 \%)$ cases had ossicular erosion, $6(6 \%)$ cases had tympanosclerosis and $1(1 \%)$ case had facial nerve dehiscence in study by Sandeep and colleagues. ${ }^{8}$

Sixteen (9.3\%) cases had oedema of middle ear mucosa/ aural polyp from middle ear. Thirteen $(13 \%)$ cases in study by Sandeep and colleagues had edema of middle ear mucosa. However, only 11 (5.3\%) cases in the study by Rout and colleagues. ${ }^{?}$

Surprisingly nine patients, i.e., 5.23\% were having cholesteatoma which was confirmed by histopathological study. Choleasteatoma was reported in the order of $8 \%$ by Sandeep and colleagues, while, Rout and colleagues reported choleasteatoma in $3.4 \%$ cases.

In a series of 1024 cholesteatoma patients described by Charles D. Bluestone, Jerome O. Klein 2007, a cholesteatoma was found in $42 \%$ in the attic in $31 \%$ in posterior superior quadrant, in $18 \%$ when it was a total perforation, in $6 \%$ when there was a central perforation and in 3\% when there was no perforation. ${ }^{22}$ In a study of 1146 cases of cholesteatoma, it is described that the perforation site on the TM is rarely central; this occurred in $13.3 \%$ of the sample. Perforation was marginal and attic in $73.6 \%$ of cases. Sadé et al found marginal and attic perforation in $84.0 \%$ of their cases. ${ }^{23}$

Cholesteatoma is a sac containing central keratin debris surrounded by keratinized squamous epithelium in the fibrous tissue matrix and which has got bone eroding property. Cholesteatoma can be classified as congenital and acquired, and acquired can be primary and secondary. Secondary cholesteatoma is commonest and is found in case of CSOM with attic and marginal perforations. Cholesteatoma formation in CSOM with central perforation is very rare. Most common sites of origin of cholesteatoma are posterior epitympanum, posterior mesotympanum, and anterior epitympanum in the order.

Tos (1988) classified cholesteatoma otoscopically which was later on modified by Mills and Padgham (1991). According to them, cholesteatoma can be of four types, i.e., attic, pars tensa I (marginal), pars tensa II (central), and behind intact tympanic membrane. ${ }^{5}$
Although a central perforation of the tympanic membrane is the typical finding of chronic otitis media without cholesteatoma, a keratinizing squamous epithelium on the tympanic side of the tympanic membrane or in the tympanic cavity is occasionally found during surgery. This finding were observed in 28 of 2948 cases with central perforation of the tympanic membrane without any other pathology indicating the possibility of cholesteatoma such as a retraction, an adhesion, or a debris accumulation around the perforation margin or in the tympanic cavity. The characteristic finding in this disease is an irregular margin of the perforation with a whitish remnant tympanic membrane. This finding was observed in $82 \%$ of these cases. If discovered preoperatively, a careful observation of the tympanic side of the tympanic membrane is necessary during surgery. ${ }^{9}$

Sudhoff et al expressed their view in that most operations can be completed in one stage by removing the cholesteatoma and then reconstructing the ossicular chain at the same time. A two-stage procedure is indicated only in special situations. When the surgeon has doubts over removal of cholesteatoma completely or, in rare cases, when it is not possible to remove all the squamous epithelium from the oval window or between the crura of the stapes, a second-look operation is recommended 1 (in children) or 2 years later. ${ }^{24}$

Hence, in surgical treatment of CSOM, it might not be possible to eliminate cholesteatoma and infections by preserving normal anatomic structures and to regain hearing function in each and every patient. Although restoration of the hearing loss and the preservation of anatomy are important aspects, eradication of the disease should be the main principle in the surgical procedures. ${ }^{25,26}$

In our series, we also followed the same principle in restoring the anatomy by performing in maximum patients the cortical mastoidectomy and tympanoplasty. But in cases of extensive disease, we gave preference to eradication of the disease by doing modified radical mastoidectomy and tympanoplasty.

\section{Limitation of the study}

This study has not been able to depict the possible causative factors responsible for these type of pathological findings in cases of CSOM with central perforation.

\section{Recommendation}

A long term prospective study is recommended to find out the causative factors responsible for the underlying pathological changes in CSOM with central perforation that would guide the surgeon to plan the surgery accordingly beforehand. Also the long term results in terms of graft 
uptake, hearing improvement and recurrence of disease must be explored.

\section{CONCLUSION}

This study describes the different types of underlying pathological findings in cases of safe type of chronic suppurative otitis media. This study also shows that cholesteatoma can be found in tubotympanic type of CSOM. Hence it is on the part of surgeon to be careful while planning surgery on their patients with CSOM (tubotympanic type), remembering that all safe CSOM might not always be safe. It is advisable to open the mastoid antrum and to do complete eradication of disease whenever clinical features are suggestive of extensive disease of middle ear cleft. This ensures prevention of further complication and helps to provide a safe ear and better hearing.

\section{REFERENCES}

1. John AF. Chronic otitis media: diagnosis and treatment. Med Clin North America 1991;75:1277-1291.

2. Hall IS and Colman BH. Diseases of nose, throat, ear and head and neck, $13^{\text {th }}$ ed. Edinburgh: Livingstone Itd; 1987.pp 231.

3. Goycoolea MV, Hueb MM and Ruah C. Definitions and terminology. Otolaryngol Clin North America 1991; 24 (4): 757-761.

4. Varshney S, Nangia A, Bist SS, Singh RK, Gupta N and Bhagat S. Ossicular chain status in chronic suppurative otitis media in adults. Indian J Otolaryngol Head Neck Surg 2010; 62;421-426.

5. Mills RP. Management of CSOM, Scott- Brown's Otolaryngology. $6^{\text {th }}$ ed, 3/10/1. Oxford: Reed Educational and Professional Publishing Ltd; 1997.

6. Kingsnorth A, Bowley D, editors. Fundamentals of head and neck surgery. In: Fundamentals of Surgical Practice. $3^{\text {rd }}$ ed. Newyork: Cambridge University Press; 2011;308.

7. RoutMR, Mohanty D, VijaylaxmiY, Kamalesh B and Chakradhar M. Prevalence of cholesteatoma in chronic suppurative otitis media with central perforation. Indian J Otol 2012;18 (1):7-10.

8. Sandeep S, Raghavendra KS, Prakash BG and Shivaram Shetty T. "How Safe is Safe Ear?: A Hospital Based Study". Int J Sci Stud 2014;2(2):31-34.

9. Yuasa Yu. Cholesteatoma with Central Perforation of Tympanic Membrane. J Otol Jpn 2005;15:129-132.
10. Kumar N, Chilke D and Puttewar MP. Clinical Profile of Tubotympanic CSOM and Its Management With Special Reference to Site and Size of Tympanic Membrane Perforation, Eustachian Tube Function and Three Flap Tympanoplasty. Indian J Otolaryngol Head Neck Surg 2012;64(1):5-12.

11. Ludman H. Applied anatomy. In: Mawson's Diseases of the Ear, $5^{\text {th }}$ ed. London: Edward Arnold; 1988;17-25.

12. Amin MN, Chowdhury WA, Sheikh MS and Abdullah M. Pattern of ENT diseases in rural. Bangladesh. Journal of BCPS 1989; 7:23-27.

13. Ludman $\mathrm{H}$. Complication of suppurative otitis media. In: Booth JB, editor. Scott Brown's Otolaryngology, $5^{\text {th }}$ ed. vol. 3. London: Butterworth; 1987; 264-91.

14. Albu S, Trabalzini $F$ and Amadori M. Usefulness of cortical mastoidectomy in myringoplasty. Otol Neurotol 2012; 33(4):604-609.

15. Islam MS, Islam MR, Bhuiyan MAR, Rashid MS and Datta PG. Pattern and degree of hearing loss in chronic suppurative otitis media. Bangladesh J Otorhinolaryngol 2010;16(2):96-105.

16. Bhat KV, Naseeruddin K, Nagalotimath US, Kumar PR and Hegde JS. Cortical mastoidectomy in quiescent, tubotympanic, chronic otitis media: is it routinely necessary? J Laryngol Otol 2008; 10:1-8.

17. Mishiro Y, Sakagami M, Kondo K, Kitahara T and Kakutani C. Long term effects after tympanoplasty with and without mastoidectomy for perforated chronic otitis media. Eur Arch Otorhinolaryngol 2009; 266:819-822.

18. Holmquist $J$ and Bergstrom $B$. The mastoid air cell system in ear surgery. Arch Otolaryngol 1978; 104:127-129.

19. Merchant SN. Chronic otitis media, ScottBrown's Otolaryngology, Head and Neck Surgery, $7^{\text {th }}$ ed., vol. 3. London: Edward Arnold (publisher's) Itd, Michael Gleeson editor; 2008. p. 3396-3399.

20. McGrew BM, Jackson $G$ and Glascock ME. Impact of mastoidectomy on simple tympanic membrane perforation repair. Laryngoscope 2004; 114:506-511.

21. Sheehy JL. Surgery of chronic otitis media. In: English G, editor. Otolaryngology, Revised ed. Vol. 1. Philadelphia: Harper and Row; 1985. pp. 1-86.

22. Bluestone and Klein. Complications and sequelae: intratemporal. In Charles.D.Bluestone, Jerome.O.Klein Eds. Otitis media in infants and children. $4^{\text {th }}$ ed. B.C.Decker Inc; 2007: 410-411.

23. Aquino JE, Cruz Filho NA and de Aquino JN. Epidemiologies of middle ear and mastoid cholesteatomas. Braz J Otolaryngol 2011; 77:341-347.

24. Sudhoff $\mathrm{H}$. Ossicular chain reconstruction, middle ear surgery. New York: Springer; 2006. p. 50.

25. Jeng FC, Tsai MH and Brown CJ. Relationship of preoperative findings and ossicular discontinuity in chronic otitis media. Otol Neurotol 2003; 24:29-32.

26. Syms MJ and Luxford WM. Management of cholesteatoma; status of the canal wall. Laryngoscope 2003; 113:443-448. 